\title{
The prevalence of delirium in patients in Iran: a systematic review and meta-analysis
}

Ebrahim Khalighi ${ }^{1}$, Asma Tarjoman ${ }^{2}$, Alireza Abdi ${ }^{3}$ \& Milad Borji ${ }^{*, 3}$

${ }^{1}$ Anesthesiologist, Department of Anesthesiology, Medicine Faculty, Ilam University of Medical Science, Ilam, IR Iran

${ }^{2}$ Student Research committee, kermanshah University of Medical Sciences, Kermanshah, IR Iran

${ }^{3}$ Department of Nursing, Faculty of Nursing \& Midwifery, kermanshah University of Medical Science, Kermanshah, IR Iran

*Author for correspondence: borji_milad@yahoo.com

\begin{abstract}
Aim: The first systematic review and meta analysis investigating the prevalence of delirium in Iran and the importance of delirium in the health status of patients. Method: This study is a review article to determine the overall prevalence of delirium in patients admitted to the hospitals in Iran, with search time frame to 12 October 2000-12 October 2018. The study examined the prevalence of delirium in general wards and ICUs of Iran according to published article in domestic and foreign journals. The methodological quality of the papers was based on a tool used in previous studies. Data was analyzed using comprehensive metaanalysis (CMA) software. Findings: The findings showed the prevalence of delirium in hospitalized patients in Iran is $21.8 \%$ (Cl: $17.5-27.5 \%)$. The prevalence of delirium in hospitalized patients in Iran based on the hospitalization in ICU is $24.7 \%$ (Cl: $18.1-32.7 \%$ ) and in the general ward is $17.5 \%$ (Cl: $13.6-22.3 \%$ ). Conclusion: Due to the relatively high prevalence of delirium in patients admitted to hospitals in Iran, prevention is necessary to reduce the incidence of delirium.
\end{abstract}

First draft submitted: 14 December 2018; Accepted for publication: 15 April 2019; Published online: 12 September 2019

Keywords: delirium • meta-analysis $\bullet$ prevalence $\bullet$ systematic review

Delirium is a disorder characterized by changes in acute changes in cognition and sensory perception, abnormal thinking and improper behavior. This condition is one of the common problems in patients admitted to ICUs with considerable prevalence [1,2]. As physicians and nurses cannot diagnose all cases of delirium [3], this disorder may not be diagnosed or diagnosed as a psychiatric disorder if no accurate evaluation is performed on the patient [4]. Delirium is a sudden outbreak associated with altered sensory perception, short-term memory impairment and turbulent behavior. The person loses focus and this disorder leads to lack of attention, temporary loss of memory, sleep disturbances, restlessness and illusion [5,6].

Early diagnosis and reduction of risk factors affecting delirium requires the knowledge and awareness of physicians and nurses of the intensive care unit about the nature of delirium syndrome, the symptoms of the disease, as well as the standard tools for screening delirium and the factors that affect it [6-9]. The causes of delirium are complex and are effected by various factors [10,11]. Among the factors affecting delirium are infection [12], age [13], pain [14], physical restraints [15], non relieved pain [16], each of which has different effects on the development of delirium.

Delirium various side effects, including increase in the hospitalization time, increase in the need for nursing care, the incidence of hospital pneumonia, the risk of falling, urinary incontinence and skin disorders [7,17-19]. Furthermore, the nurses working in ICUs have more stress in the care for patients with delirium [20]. Although about $30-40 \%$ of delirium can be prevented [13,21,22], most hospitals do not have a systematic protocol for preventing delirium $[4,13,23,24]$. Thus, attention to delirium is of significant importance [25].

Nursing interventions can reduce the amount of delirium in patients by simulating the environment [6] including for family-centered orientation programs [26] and music therapy [27,28]. Considering the important role of nurses in delirium management, it is necessary to have complete information about the prevalence of this disease [29]. In order to reduce the amount of delirium, its prevalence should be carefully identified and detailed and accurate information should be provided. 


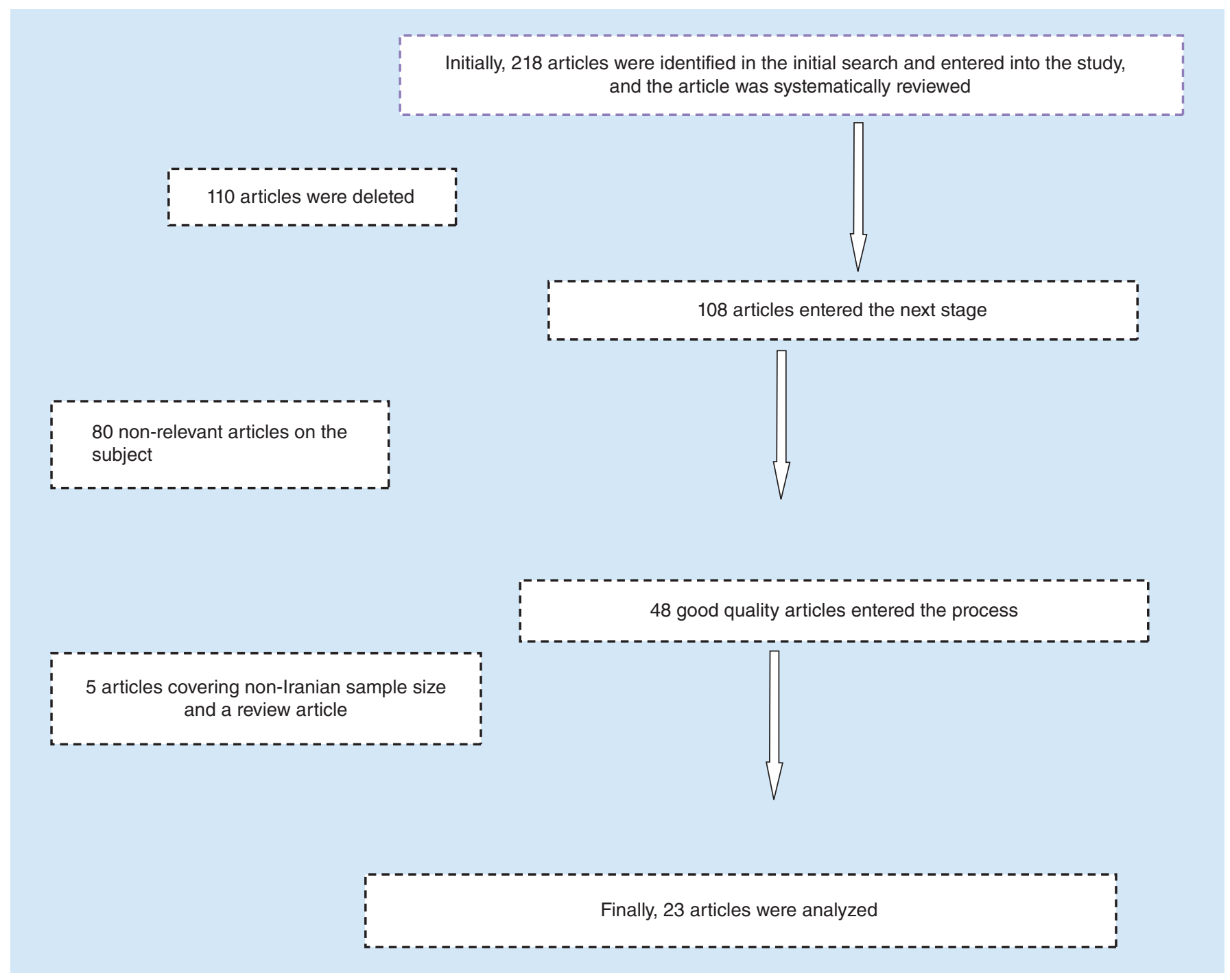

Figure 1. Flowchart for systematic review and meta-analysis.

In previous studies in Iran, reviews article of delirium have not been conducted, but in other countries, the prevalence has been studied, so that in reviews article by Krewulak et al. [30] and Systematic Review by Fadayomi et al. [31] in the field of delirium. The mentioned studies [30,31] have been carried out in other countries and in Iran there has not been a study aimed at determining the prevalence of delirium through systematic review. For this reason, the present study is innovative.

\section{Aim}

Considering the importance of delirium in improving the health status of patients, and as no studies have been conducted on the prevalence of delirium in Iran, the present study was conducted as the first systematic and meta-analytic review study in this regard.

\section{Methods}

\section{Study protocol}

This study is a systematic review with PRISMA guidelines [32] to determine the prevalence of delirium in patients admitted to the hospitals in Iran, with search time frame to 12 October 2000-12 October 2018 (Figure 1). 


\begin{tabular}{|c|c|c|c|c|c|}
\hline Study no. & Study (year) & Place & Group by ward & $\mathbf{n}$ & $\%$ prevalence \\
\hline 1 & Jannati (2013) [37] & Mazandaran & Patients undergoing open heart surgery & 404 & 28.5 \\
\hline 2 & Jodati (2013) [38] & Tabriz & Open heart surgery & 329 & $4.9 \%$ \\
\hline 3 & Modabernia (2002) [39] & Rasht & Admitted to the intensive cardiac care unit & 245 & 13.4 \\
\hline 4 & Bagheri (2017) [40] & Isfahan & Patient candidate for cardiopulmonary bypass & 100 & 34 \\
\hline 5 & Cheraghi (2015) [41] & Tehran & Undergoing cardiac surgery & 40 & 22.5 \\
\hline 6 & Asaee (2008) [42] & Khoramabad & Patients admitted to internal and surgical departments & 240 & 25.83 \\
\hline 7 & Hosseini (2016) [43] & Yazd & General surgery, gynecology, orthopedics, internal medicine, ICU & 256 & 14.8 \\
\hline 8 & Heidari (2014) [44] & Isfahan & Patients admitted to the intensive care unit & 270 & 44.5 \\
\hline 9 & $\begin{array}{l}\text { Rajabpour Nikfam } \\
\text { (2014) [45] }\end{array}$ & Rashat & Patients admitted to the intensive care unit & 148 & 27.2 \\
\hline 10 & Foroughan (2015) & Ahvaz & General hospital & 200 & 22 \\
\hline 11 & $\begin{array}{l}\text { Eizadi-Mood } \\
\text { (2014) }[46]\end{array}$ & Isfahan & Coronary artery bypass graft surgery & 325 & $44.31 \%$ \\
\hline 12 & Hosseini (2011) [47] & Sari & Total hospital patients & 600 & 16 \\
\hline 13 & Shadvar (2013) [48] & Tabriz & ICU following cardiac surgery & 200 & 23.5 \\
\hline 14 & Salari (2017) [49] & Rasht & Patients undergoing elective cardiac surgery & 108 & 38 \\
\hline 15 & $\operatorname{Rad}(2014)[50]$ & Tehran & Open heart surgery in special sections & 370 & 23.24 \\
\hline 16 & Beiranvand (2013) [51] & Khorramabad & $\begin{array}{l}\text { Patients admitted to intensive care unit that are under general } \\
\text { surgery and hip surgery }\end{array}$ & 200 & 24 \\
\hline 17 & Rezvani (2016) [52] & Isfahan & Patients admitted to the intensive care unit & 100 & 46 \\
\hline 18 & Mohaamadi (2003) [53] & Azarbayjan gharbi & Patient admitted to surgery for advanced head and neck cancer & 104 & 9.6 \\
\hline 19 & Hassani (2010) [54] & Orumieh & Heart surgery & 514 & 2.33 \\
\hline 20 & Ganavati (2009) [55] & Tehran & CABG surgery & 250 & 47 \\
\hline 21 & Ashraflashkari [56] & Ahvaz & Open heart surgery and general surgery department & 60 & 6.66 \\
\hline 22 & Beyraghi (2004) [57] & Tehran & General hospital psychiatry & 201 & 15 \\
\hline 23 & Jouybari (2012) [58] & Gorgan & General surgery and recovery & 75 & 30.6 \\
\hline
\end{tabular}

\section{Search strategy}

The study with aim the prevalence of delirium in general wards and ICUs of Iran according to published article in domestic and foreign journals. The search for papers was done independently by a nurse and an anesthetist to prevent any kind of bias, and if there was a controversy between the two researchers, the specialized search was done by a third colleague specialist in systematic and meta-analytic review studies.

\section{Inclusion criteria \& data extraction}

At the beginning of the search all articles regarding delirium in Persian and English on the internal databases of Iran (such as IranDoc, SID, Magiran and Iranmedex) and international databases (such as Springer, Science Direct, Medlib, Scopus, PubMed, Ebsco, Web of Science, Wiley Online Library and Cochrane) were gathered. The keywords were 'delirium', 'prevalence', 'Iran' and a combination of them. It should be noted that the references of the articles were evaluated to improve the quality of the search. In this study, interventional and observation articles, letters to the editor, presented in the summary of congresses, as well as existing dissertations, were excluded from the study. Exclusion criteria were irrelevance to the subject, case reports, being interventional, extracted papers being qualitative, and repetitive studies.

The methodological quality of the papers was based tool had five study design items, a comparison group, and descriptions of the characteristics of sample studied, sample size and the tools used. Each item received a score of 0-3, with the higher score showing a higher quality of the methodology of studies [33-36].

\section{Data extraction}

After the extraction of the studies the papers were recorded using a checklist with the name of the author, the paper publication year, the location (ward) of the patients under study, the sample size and the prevalence of delirium.

The ethical considerations in the study were observing ethics in research in the publication of results and obtaining a code of ethics from Kermanshah University of Medical Sciences. 


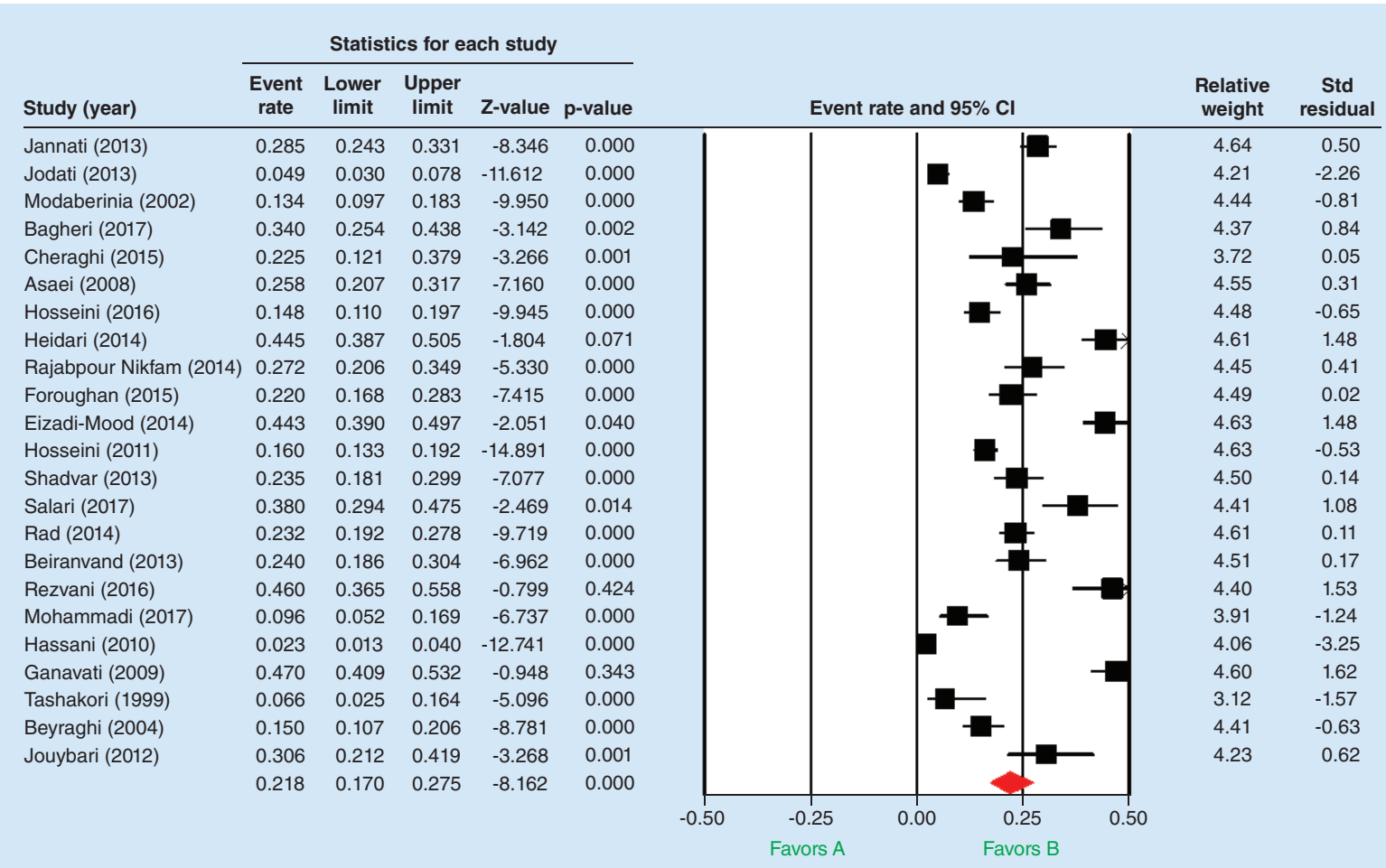

Meta analysis

Figure 2. Prevalence of delirium in hospitalized patients in Iran.

\section{Statistical analysis}

Comprehensive meta-analysis (CMA) software was applied to data analysis. Heterogeneity of prevalence of delirium was checked by tests of Cochran's Q I ${ }^{2}$ (the heterogeneities of the studies were divided into; less than 25\% (low heterogeneity), 25\% to 75\% (moderate heterogeneity) and more than 75\% (high heterogeneity). Regarding the high heterogeneity $\left(\mathrm{I}^{2}=94.88, \mathrm{Q}=430.02 \mathrm{~m}, \mathrm{p}<0.001\right)$ we used DerSimonian and Laird's random effects model to combine the studies prevalance, Kendal's tau in Begg and Manzumdar test and Funnel plot were applied for checking the publication bias.

\section{Findings}

In this paper, 23 studies between 2000 and 2018 were introduced into a quantitative meta-analysis process. 5339 patients were included in these studies in total (Table 1). The Cheraghi et al. (2015) study had the lowest number of patients at 40, whilst the Hosseini et al. (2011) had 600 patients, making this the study with the most patients. The highest prevalence of delirium was found in Heidari et al. (2014) in Isfahan with a prevalence of $44.5 \%$ and the lowest prevalence rate in Ashraflashkari et al. in Ahwaz, with an incidence of $6.66 \%$. Studies with numbers 1-2-4-5-11-14-15-19-20 have the same hospitalization characteristics due to one type of heart disease and studies with numbers 3-7-8-9-16-17 admitted to intensive care units. Table 1 shows the characteristics of the articles used in this study. According to the findings of the study, 23 studies were conducted to investigate the prevalence of delirium in general and special sectors (Table 1).

The findings of Figure 2 show the prevalence of delirium in hospitalized patients in Iran. According to the findings, this figure is 21.8\% (CI: 17.5-27.5\%; Q $=430.029 \mathrm{p}<0.001, \mathrm{I}^{2}=94.884, \mathrm{Z}=8.162, \mathrm{p}<0.001$ ).

The findings of Figure 3 show the prevalence of delirium in hospitalized patients in Iran based on hospitalization in critical care units. According to the findings, this figure is $24.7 \%$ (CI: $18.1-32.7 \%$ ) and in the general ward is 17.5\% (CI: 13.6-22.3\%). The findings of Figure 4 show the bias in the publication of the articles $(\mathrm{Z}=1.58, \mathrm{p}$ $=0.113)$. 


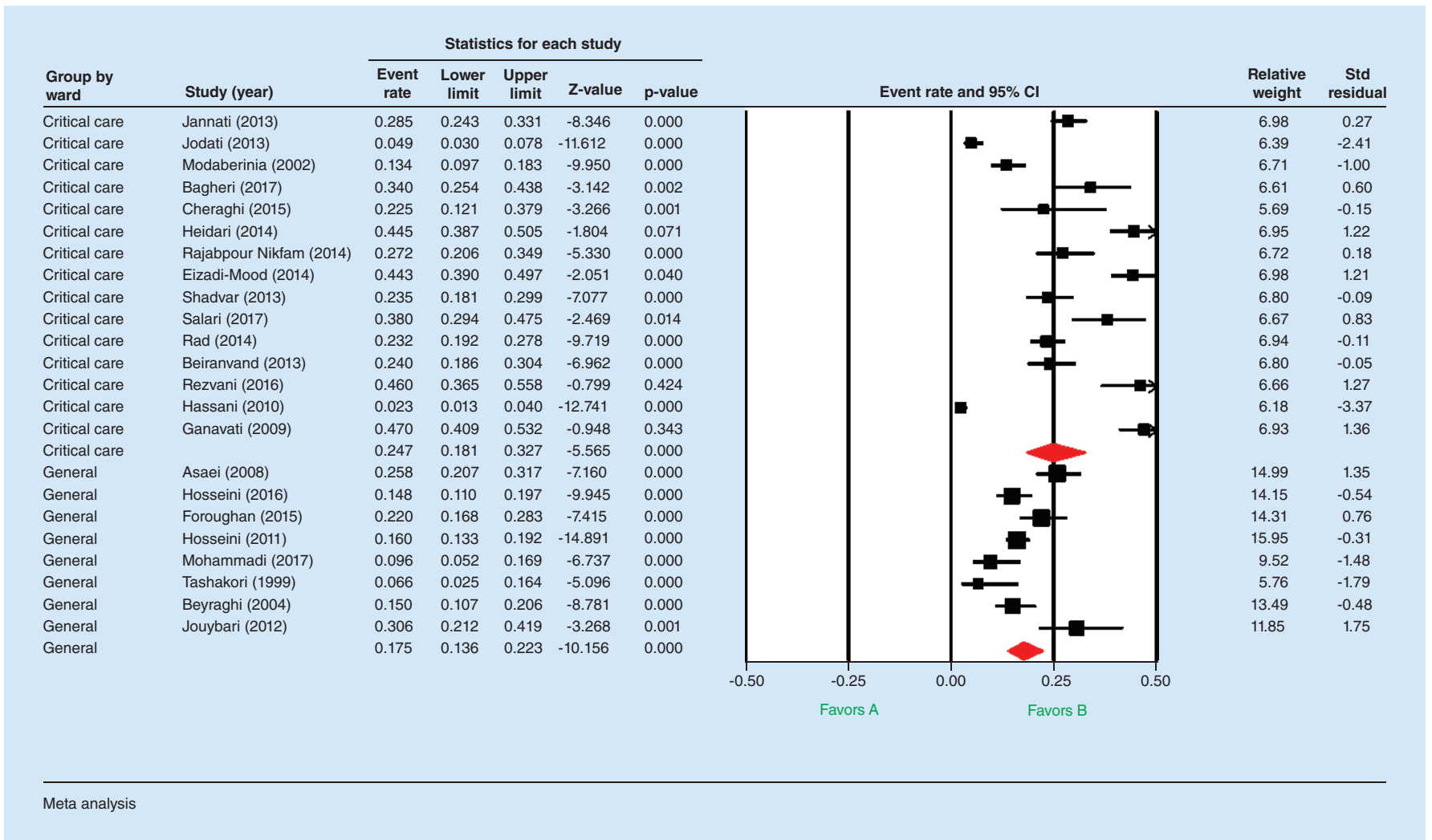

Figure 3. Prevalence of delirium based on hospital ward.

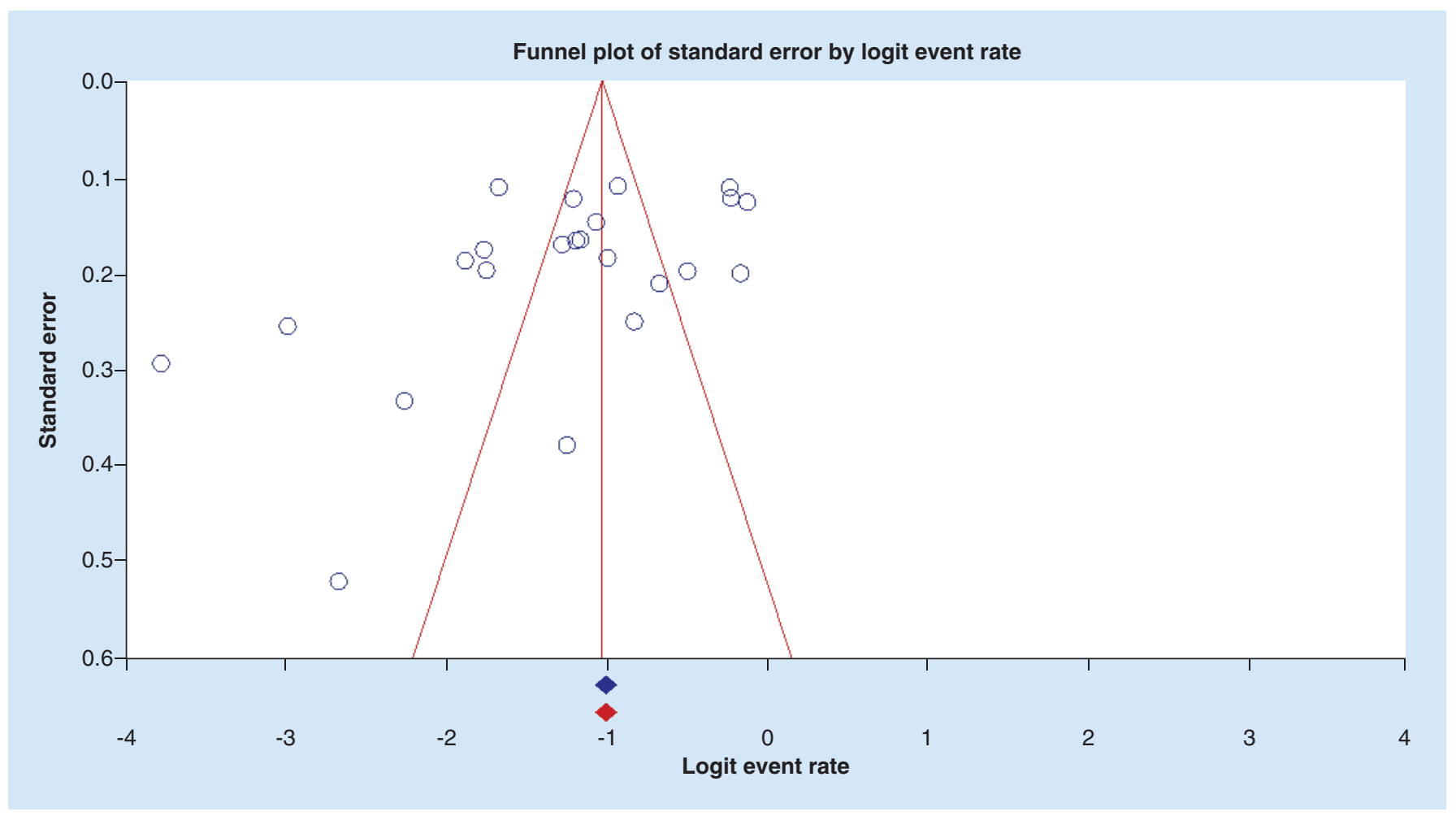

Figure 4. Characteristics of the bias in the publication of articles. 


\section{Discussion}

Meta-analysis studies provide researchers with relevant evidence [57]. The findings showed that the prevalence of delirium in Iran was $21.8 \%$, which is relatively high. The rate in special critical care units is $24.7 \%$ and in the general unit is $17.5 \%$. Delirium causes complex complications for patients, which is why it is very important to pay attention $[59,60]$.

According to the findings of this study, the delirium prevalence in critical care was $24.7 \%$, consistent with the results of the study by Collet et al. [61]. Delirium outbreaks in critical wards was found to be $19 \%$ in Tilouche and colleagues in Tunisia [62], which is less than the results of the present study. In some studies, the prevalence of delirium in these wards was much higher than the present study. For example, the McNicoll et al. study in the USA reported a prevalence of $31 \%$ [63]. In a study by Limpawattana et al. in Thailand, it was 44.4\% [52,64], in Ely et al. in the USA, it was $81.3 \%$ [65], in Thomason et al. in the USA it was 48\% [66], in the study by Micek et al., it was $47 \%$ [67] and it was $45 \%$ in the Roberts study [68]. The difference between Tilouche and colleagues [62] and Ely et al. [65] with the results of the present study can be noted that the study was a cross-sectional descriptive study and examined a specific number of patients with a sample size of 206 and 48 patients. While the present study is a systematic review study with a sample size of 5339 patients, other differences can be noted that in the present study patients in different units have been studied. In the studies mentioned, only patients in the intensive care units have been examined.

One of the strengths of the present study is that the delirium prevalence has been investigated in all parts of the hospital and can provide useful information in this regard. The weaknesses of this study can be attributed to the diversity of studies (considering simple randomized sampling studies), which has led to the creation of heterogeneity. The researcher has analyzed the subgroup to reduce the amount of heterogeneity and provide more accurate findings based on the type of hospitalization. Other strengths of this study are the fact that the delirium prevalence has been studied over a long period of time. In this study, the delirium 18-year prevalence in Iran was studied. One of the weak point of this study is that the same tool was not used to study the delirium prevalence, and the method of conducting studies that make up the review varied.

Due to the fact that the delirium prevalence rate was significant in the study, it is recommended that screening be performed at the beginning of the patient's arrival in the hospital. After that, nurses will receive the necessary training for each patient. It is also suggested that necessary educational interventions for nurses and nursing students should be made to become acquainted with the importance of delirium and so the necessary measures can be taken to reduce this.

Following on from this paper, it is suggested that global studies should be conducted on the prevalence of delirium in different countries. It is also suggested that the results of the delirium prevalence in Iran be compared with other countries.

\section{Conclusion}

The findings show the prevalence of delirium in hospitalized patients in Iran is $21.8 \%$ (CI: 17.5-27.5\%). Due to the relatively high prevalence of delirium in patients admitted to hospitals in Iran, prevention is necessary to reduce the incidence of delirium.

\section{Summary points}

- The present study investigates the prevalence of delirium in patients in Iran.

- The findings show the prevalence of delirium in hospitalized patients in Iran is $21.8 \%$ (CI: 17.5-27.5\%).

- The findings show the prevalence of delirium in hospitalized patients in Iran based on the hospitalization in ICU according to the findings is $24.7 \%(\mathrm{Cl}: 18.1-32.7 \%)$ and in the general ward is $17.5 \%$ (Cl: $13.6-22.3 \%)$.

- Due to the relatively high prevalence of delirium in patients admitted to hospitals in Iran, prevention is necessary to reduce the incidence of delirium.

Financial \& competing interests disclosure

This study was approved by Student Research committee of research deputy of Kermanshah University of Medical Sciences, Kermanshah, IR Iran with Grant Number: 30097769. The authors thank the officials of this committee and research deputy. The authors have no other relevant affiliations or financial involvement with any organization or entity with a financial interest in or financial conflict with the subject matter or materials discussed in the manuscript apart from those disclosed.

No writing assistance was utilized in the production of this manuscript. 


\section{Ethical conduct}

Research ethics committee of Kermanshah University of Medical Sciences approved this study with ethics code of IR.KUMS.REC.1397.837.

\section{Open access}

This work is licensed under the Creative Commons Attribution-NonCommercial-NoDerivatives 4.0 Unported License. To view a copy of this license, visit: http://creativecommons.org/licenses/by-nc-nd/4.0/

\section{References}

1. von Gunten A, Mosimann UP, Antonietti J-P. A longitudinal study on delirium in nursing homes. Am. J. Geriatr. Psychiatry 21(10), 963-972 (2013).

2. Urden LD, Stacy KM, Lough ME. Thelan's Critical Care Nursing: Diagnosis and Management. Mosby, MO, USA (2006).

3. Van Rompaey B, Schuurmans MJ, Shortridge-Baggett LM, Truijen S, Elseviers M, Bossaert L. A comparison of the CAM-ICU and the NEECHAM confusion scale in intensive care delirium assessment: an observational study in non-intubated patients. Crit. Care 12(1), R16 (2008).

4. Jannati Y, Sohrabi M, Bagheri-Nesami M. Delirium and its diagnostic tools: a new approach to nursing. Clin. Excellence 1(2), 85-96 (2013).

5. Khan BA, Zawahiri M, Campbell NL, Fox GC, Weinstein EJ, Nazir A et al. Delirium in hospitalized patients: implications of current evidence on clinical practice and future avenues for research - a systematic evidence review. J. Hosp. Med. 7(7), 580-958 (2002).

6. Zeighami R, Alipour Heydari M, Babaee R. The effect of a multifactorial intervention on the incidence of delirium in cardiac surgery unit. J. Nurs. Educ. 3(4), 48-57 (2006).

7. Zolfaghari M, Arbabi M, Pedram Razi S, Biat K, Bavi A. Effectiveness of a multifactor educational intervention on delirium incidence and length of stay in patients with cardiac surgery. J. Hayat. 18(1), 67-78 (2012).

8. Ettema R, van Harten D, Hoogerduijn J, Hoekstra T, Schuurmans M. Nurses opinions regarding delirium care in the older general hospital population and in older cardiac surgery patients specifically: a multicentre survey among Dutch nurses. Int. J. Clin. Exp. Med. 5(21), 1352 (2014).

9. Lu JH, Chan DK, O’Rourke F, Ong B, Shen Q, Reutens S et al. Management and outcomes of delirious patients with hyperactive symptoms in a secured behavioral unit jointly used by geriatricians and pyschogeriatricians. Arch. Gerontol. Geriatr. 52(1), 66-70 (2011).

10. Paterson R, Long D, Schibler A, De Young A, Dow B, Warren J et al. Risk factors for delirium in an Australian paediatric intensive care unit. Australian Crit. Care 31(2), 117 (2018).

11. Lau T, Russell S. A complex case of delirium: from theory to clinical management. In: Shivakumar K, Amanullah S (Eds). Complex Clinical Conundrums in Psychiatry, Springer, Cham, Switzerland (2018).

12. Van Gool WA, Van de Beek D, Eikelenboom P. Systemic infection and delirium: when cytokines and acetylcholine collide. Lancet 375(9716), 773-775 (2010).

13. Inouye SK, Westendorp RG, Saczynski JS. Delirium in elderly people. Lancet 383(9920), 911-922 (2014).

14. Kosar CM, Tabloski PA, Travison TG et al. Effect of preoperative pain and depressive symptoms on the risk of postoperative delirium: a prospective cohort study. Lancet Psychiatry 1(6), 431-436 (2014).

15. Schiemann A, Hadzidiakos D, Spies C. Managing ICU delirium. Curr. Opin. Crit. Care 17(2), 131-140 (2011).

16. Cheraghi MA, Hazaryan M, Bahramnezhad F, Mirzaeipour F, Haghani H. The relationship between pain and the incidence of delirium in patients undergoing cardiac surgery. Med. Surg. Nurs. J. 4(3), 43 (2015).

17. Pieralli F, Vannucchi V, Mancini A, Grazzini M, Paolacci G, Morettini A et al. Delirium is a predictor of in-hospital mortality in elderly patients with community acquired pneumonia. Intern Emerg. Med. 9(2), 195-200 (2014).

18. Bail K, Berry H, Grealish L, Draper B, Karmel R, Gibson D et al. Potentially preventable complications of urinary tract infections, pressure areas, pneumonia, and delirium in hospitalised dementia patients: retrospective cohort study. BMJ Open 3(6), e00277 (2013).

19. Balas MC, Deutschman CS, Sullivan-Marx EM, Strumpf NE, Alston RP, Richmond TS. Delirium in older patients in surgical intensive care units. J. Nurs. Scholarsh. 39(2), 147-154 (2007).

20. Zamoscik K, Godbold R, Freeman P. Intensive care nurses' experiences and perceptions of delirium and delirium care. Intensive Crit. Care Nurs. 40, 94-100 (2017).

21. Inouye SK, Bogardus Jr ST, Charpentier PA, Leo-Summers L, Acampora D, Holford TR et al. A multicomponent intervention to prevent delirium in hospitalized older patients. N. Engl. J. Med. 340(9), 669-676 (1999).

22. Marcantonio ER, Flacker JM, Wright RJ, Resnick NM. Reducing delirium after hip fracture: a randomized trial. J. Am. Geriatr. Soc. 49(5), 516-522 (2001).

23. Reston JT, Schoelles KM. In-facility delirium prevention programs as a patient safety strategy: a systematic review. Ann. Intern. Med. 158(5 Part 2), 375-380 (2013). 
24. Adib-Hajbaghery M, Ghapani S, Poorabbasi M. The effects of environmental simulation on delirium incidence after coronary artery bypass graft surgery. J. Urmia Nurs. Midwifery Fac. 16(5), 303-13 (2018).

25. Kang J, Lee M, Ko H, Kim S, Yun S, Jeong Y et al. Effect of nonpharmacological interventions for the prevention of delirium in the intensive care unit: a systematic review and meta-analysis. J. Crit. Care 48, 372-384 (2018).

26. Karimi V, Hanifi N, Bahraminejad N, Faghihzadeh S. The effect of family-centered orientation program on prevention of delirium prevalence in patients with coronary artery disease: a clinical trial. Military Caring Sci. 2(2), 104-114 (2015).

27. Johnson K, Fleury J, McClain D. Music intervention to prevent delirium among older patients admitted to a trauma intensive care unit and a trauma orthopaedic unit. Intensive Crit. Care Nurs. 47, 7-14 (2018).

28. Fraser V, Cossette S, Mailhot T, Brisebois A, Dubé V. Evaluation of an intervention with nurses for delirium detection after cardiac surgery. Worldviews Evid. Based Nurs. 15(1), 38-44 (2018).

29. Norman SL, Taha AA. Delirium knowledge, self-confidence, and attitude in pediatric intensive care nurses. J. Pediatr. Nurs. 46, 6-11 (2019).

30. Krewulak KD, Stelfox HT, Leigh JP, Ely EW, Fiest KM. Incidence and prevalence of delirium subtypes in an adult ICU: a systematic review and meta-analysis. Crit. Care Med. 46(12), 2029-2035 (2018).

31. Fadayomi AB, Ibala R, Bilotta F, Westover MB, Akeju O. A systematic review and meta-analysis examining the impact of sleep disturbance on postoperative delirium. Crit. Care Med. 46(12), e1204-e12 (2018).

32. PRISMA. PRISMA Checklist. http://prisma-statement.org/PRISMAStatement/Checklist.aspx

33. Gheshlagh RG, Ebadi A, Dalvandi A et al. The relationship between mental health and resilience: a systematic review and meta-analysis. Iran Red Crescent Med. J. 19(6), e13537 (2017).

34. Hoodin F, Weber S. A systematic review of psychosocial factors affecting survival after bone marrow transplantation. Psychosomatics 44(3), 181-195 (2003).

35. Tsimicalis A, Stinson J, Stevens B. Quality of life of children following bone marrow transplantation: critical review of the research literature. Eur. J. Oncol. Nurs. 9(3), 218-238 (2005).

36. Ghanei Gheshlagh R, Nazari M, Baghi V, Dalvand S, Dalvandi A, Sayehmiri K. Underreporting of needlestick injuries among healthcare providers in Iran: a systematic review and meta-analysis. J. Hayat. 23(3), 201-213 (2017).

37. Janati Y, Bagheri NM, Sohrabi M, Yazdani CJ, Mazdarani S. Factors associated with post-surgical delirium in patients undergoing open heart surgery. Oman Med J. 9(5), 340-345 (2014).

38. Jodati A, Safaie N, Raoofi M et al. Prevalence and risk factors of postoperative delirium in patients undergoing open heart surgery in northwest of Iran. J. Cardiovasc. Thorac. Res. 5(3), 97-99( 2013).

39. Modabernia M, Forghan Parast K, Khalkhali S, Najafi K. Delirium in CCU. J. Guilan Univ. Med. Sci. 11(41), 1-6 (2002).

40. Bagheri K, Honarmand A, Hosseini MSJ. Association of mean arterial pressure during cardiopulmonary pump and incidence of delirium after coronary artery bypass graft surgery. 35(449), 1358-1363 (2017).

41. Cheraghi MA, Hazaryan M, Bahramnezhad F, Mirzaeipour F, Haghani H. Study of the relationship between sleep quality and prevalence of delirium in patients undergoing cardiac surgery. Health Sci. 5(9S), 38-43 (2016).

42. Asaee R, Nasari H, Hoseini S. Prevalence of delirium in hospitalized internal medicine and surgical adult patients in Shohadaye ashayer hospital of Khoram abad. Yafteh 10(3), 21-27 (2008).

43. Hosseini F, Shajari A, Hosseini BS. Investigation of the frequency of delirium in different departments in the Yazd Shohadaye Kargar Hospital. SSU J. 24(8), 640-648 (2016).

44. Heidari A, Dianati M, Mousavi G. Prevalence of delirium, its related factors and short-term outcomes in ICU wards of Kashan Shahid-Beheshti and Isfahan Kashani hospitals during 2012-2013. Feyz J. Kashan Univ. Med. Sci. 18(1) 76-84 (2014).

45. Rajabpour Nikfam M, Ghanbari Khanghah A, Khaleghdoost Mohammadi T, Kazemnezhad Leili E, Ashraf A. Study of predictors of delirium incidence in hospitalized patients in intensive care units. J. Holistic Nurs. Midwifery 26(3), 25-35 (2014).

46. Eizadi-Mood N, Aghadavoudi O, Najarzadegan MR, Fard MM. Prevalence of delirium in opium users after coronary artery bypass graft surgery. Int. J. Prev. Med. 5(7), 900 (2014).

47. Hosseini SH, Mortazavi M. Frequency of referral rate and psychiatric diagnoses in Sari Imam Khomeini Hospital during 2008 and 2009. J. Mazandaran Univ. Med. Sci. 20(80), 63-68 (2011).

48. Shadvar K, Baastani F, Mahmoodpoor A, Bilehjani E. Evaluation of the prevalence and risk factors of delirium in cardiac surgery ICU. J. Cardiovasc. Thorac. Res. 5(4), 157 (2013).

49. Salari A, Hasandokht T, Dadkhah Tirani H, Nourisaeed A, Javadzadeh Moghtader A. The incidence of delirium after heart bypass surgery in patients with preoperative anxiety and depression. J. Guilan Univ. Med. Sci. 26(101), 36-45 (2017).

50. Rad M, Mohammadi N, Seyyedshohadaee M, Haghani H. Relationship of blood transfusion and CPB with delirium. 20(5), 801-807 (2014). 
51. Beiranvand A, Fallahi Khoshkneb M, Ashayeri H, Rahgozar M. Comparison between prevalence of delirium after hip surgery and general surgery in hospitalized female elderly. Geriatric Nurs. 1(1), 83-93 (2014).

52. Rezvani M, Alikiaii B, Ramezani S. The relationship of erythrocyte sedimentation rate (ESR) and c-reactive protein (CRP) with an uncertain prognosis for the patients admitted to the intensive care unit in Alzahra hospital, Isfahan, Iran, during 2014-2015. 34(391), 835-840 (2016).

53. Mohammadi M. Epidemiology of psychiatric disorders in West Azarbaijan Province (2001). Urmia Med. J. 14(4), 9-15 (2003).

54. Hassani E, Mahoori A, Noroozinia H, Mehdizadeh H, Sepasi N. Evaluation of risk factors for adverse neurologic outcome after cardiac surgery. Urmia Med. J. 21(2), 249-253 (2010).

55. Ganavati A, Foroughi M, Esmaeili S, Hasantash S, Bolourain A, Shahzamani M et al. The relation between post cardiac surgery delirium and intraoperative factors. Irnanian J. Surg. 17 16-25 (2009).

56. Tashakori A. Comparison of the incidence of postoperative delirium in patients with open heart surgery and general surgery in Ahvaz Golestan Hospital in 1999. Jundishapur Sci. Med. J. 41(41), 37-43 (1999).

57. HatefiBadfar GShohani M Nasirkandy M et al. Epidemiology of hepatitis B in pregnant Iranian women: a systematic review and meta-analysis. Arch. Virol. 24163(32), 1319-330 (2019).

58. Jouybari L, Hosseini SFH, Ghana S, Saeedi S, Sanagoo A. The incidence of delirium in patients after surgery in recovery room. Jorjani 1(1), 23-29 (2012).

59. Gleason LJ, Schmitt EM, Kosar CM, Tabloski P, Saczynski JS, Robinson T et al. Effect of delirium and other major complications on outcomes after elective surgery in older adults. JAMA Surg. 150(12), 1134-1140 (2015).

60. Marcantonio ER. Delirium in hospitalized older adults. N. Engl. J. Med. 377(15), 1456-1466 (2017).

61. Collet MO, Caballero J, Sonneville R, Bozza FA, Nydahl P, Schandl A et al. Prevalence and risk factors related to haloperidol use for delirium in adult intensive care patients: the multinational AID-ICU inception cohort study. Intensive Care Med. 44(7), 1081-1089 (2018).

62. Tilouche N, Hassen MF, Ali HBS, Jaoued O, Gharbi R, El Atrous SS. Delirium in the intensive care unit: incidence, risk factors, and impact on outcome. Indian J. Crit. Care Med. 22(3), 144 (2018).

63. McNicoll L, Pisani MA, Zhang Y, Ely EW, Siegel MD, Inouye SK. Delirium in the intensive care unit: occurrence and clinical course in older patients. J. Am. Geriatr. Soc. 51(5), 591-598 (2013).

64. Limpawattana P, Panitchote A, Tangvoraphonkchai K, Suebsoh N, Eamma W, Chanthonglarng B et al. Delirium in critical care: a study of incidence, prevalence, and associated factors in the tertiary care hospital of older Thai adults. Aging Ment. Health 20(1), 74-80 (2016).

65. Ely E, Gautam S, Margolin R, Francis J, May L, Speroff T et al. The impact of delirium in the intensive care unit on hospital length of stay. Intensive Care Med. 27(12), 1892-1900 (2016).

66. Thomason JW, Shintani A, Peterson JF, Pun BT, Jackson JC, Ely EW. Intensive care unit delirium is an independent predictor of longer hospital stay: a prospective analysis of 261 non-ventilated patients. Crit. Care 9(4), R375 (2005)

67. Micek ST, Anand NJ, Laible BR, Shannon WD, Kollef MH. Delirium as detected by the CAM-ICU predicts restraint use among mechanically ventilated medical patients. Crit. Care Med. 33(6), 1260-1265 (2005).

68. Roberts B, Rickard CM, Rajbhandari D et al. Multicentre study of delirium in ICU patients using a simple screening tool. Australian Crit. Care. 18(1), 6-16 (2018). 